\title{
CLINICAL, HAEMATOLOGICAL AND PATHOLOGICAL CHANGES FOLLOWING BILATERAL URETERAL LIGATIONIN BORNO WHITE GOATS- A PRELIMINARY REPORT.
}

\author{
A. MOHAMMED ${ }^{1}$ I.O. IGBOKWE ${ }^{2}$ and Y.B. MUSA ${ }^{1}$ \\ ${ }^{1}$ Department of Veterinary Surgery and Reproduction \\ ${ }^{2}$ Department of Veterinary Pathology. \\ Received 2 May, 1991, accepted 4 June 1991).
}

\begin{abstract}
Bilateral ureteral ligation was performed through the left paralumber fossa in 4 clinically healthy adult Borno White goats. Clinical effects or uraemia were observed 24 hours after surgery when anuria had set in and included inappetence, depression, coughing, stretching of the neck, laboured breathing with inspiratory wheezing sound, serous to mucous ocular and nasal discharges, and terminal paralysis and convulsion. Haematological changes observed included anaemia from day 2 after surgery and lymphocytosis on days 1 and 2, leucocytosis on day 3 , neutrophilia on days 3 and 5 and eosinopenia on days 9 and 11 after Surgery. At post-mortem, the major lesions observed were bronchopneumonia, renal tubular necrosis and gastroenteritis.
\end{abstract}

\section{INTRODUCTION}

Extrarenal lesions associated with renal failure in ruminants have been shown to differ from those in monogastric animals (Watts and Campbell, 1970,1971) and they vary between and within species (Blood et al, 1983). The patholoogical effect of urinary retention has been previously studied following experimental bilateral nephrectomy or ureteral ligation in cattle, sheep and goats (Vyas et al., 1978; Jalaluddin et al., 1986). This paper reports the clinical signs, haematological and pathlogical changes following bilateral ureteral ligation in Borno White goats to assist the clinician in assessing the prognosis of anuric patients among this breed.

\section{MATERIALS AND METHODS}

Four clinically health Borno White goats weighing $10-14 \mathrm{~kg}$ and aged $1.5-2.0$ years were used.

Nigeria Journal of Animal Production 18 (1991)
The goats were purchased from the livestock market in Maiduguri. They were housed in concrete-floored pens and dosed with morental tartrate (Banmith, Pfizer, Nigeria). They were fed groundnut hay and maize bran and water was given ad libitum. They were observed for 2 weeks before the experiment.

Bilateral ureteral ligation was performed through the left paralumber fossa using chlorpromazine hydrochloride (Largactil, May and Baker, England) as sedative and Lignocaine hydrochloride (Xylocaine, Astra, Sweden) as local anaesthetic respectively.

Blood samples $(2.5 \mathrm{ml})$ were collected with ethlene diamine tetra-acetate (EDTA) as anticooagulant before surgery and every 24 hours for 3 days after surgery and every 48 hours subsequently until death. With the blood samples, the packed cell volume (PCV) was determined by microhaematocrit method, haemoglobin (HB) concentration by cyanmethaemoglobin method, the white blood cell count was done by haemocytometry and the differential white blood cell count was done using blood films stained with Giemsa stain (Schalm et al., 1975).

Clinical signs were observed until death. After death, post-mortem examination was carried out and tissue specimens were collected and fixed in $10 \%$ formalin. The tissues were processed, $\mathrm{cm}$ bedded and cut at 5 - 10 microns and stained with haemotoxylin and eosin for histopathological examination (Druby and Wallington 1967). Data was summarized as Mean \pm standard deviation (SD) and significant difference assessed by t-test (Charfield, 1983). 


\section{RESULTS}

\section{Clinica! Signs:}

The goats recovered fully from anaesthesia within 2-6 hours after Surgery. They were alert and maintained normal appetite for about 24 hours after which there was inappetence. They were completely anorexic a day befure death. The animals were depressed at about 24 hours after Surgery and coughing. stretching of neck, inspiratory wheezing sound and laboured breathing were observed. There was bilateral serous ocular and nasal discharges which became mucopurulent as the condition progressed. Other clinical signs included grinding of teeth, slight urine- like odour of breath, copious salivation, ruminal atony, rough hair coat, anuria and weakness. Scanty faeces of hard consistency were voided. Few hours before death, there was paralysis of the limbs followed by brief convulsion. The goats died between 86 and 302 hours after surgery.

The changes in the haematological parameters after the surgery are presented in Table 1 . There were significant decreases $(\mathrm{P}<0.05)$ in $\mathrm{PCV}$ from day 2 onwards and in HB on day 5. There were significant increases $(P<0.05)$ in the WBC count un day 3 . neutrophil (segmented) count on days 3 and 5, lymphocyte count on days 1 and 2 after surgery. There were no significant variations in the monocyte count. The eosinophil count significantly decreased $(\mathrm{P}<0.05)$ on days 9 and 11 after Surgery.

\section{Gross Lesions:}

The carcasses were emaciated and the visible mucous membranes were pale. The abdominal and thoracic cavities contained $40-1100 \mathrm{ml}$ and $15-40 \mathrm{ml}$ of serous fluid respectively. The trachea and bronchi contained frothy creamy exudate and the mucosae were congested. The ventral parts of the cranial and cardiac lobes of the lungs wer congested, oedematous and consolidated and there was adhesion of this part to the thoracic wall in one goat.

The liver was enlarged and congested. There was accumulation of serous fluid between the renal capsule and the parenchyma. The kidneys were enlarged and ooedematous with focal pale necrotic area of about $3 \mathrm{~mm}$ diameter on the caudal poles. The urinary bladder was shrunkened and contained a creamy pus. The bone marrow was fatty and the brain was congested and oedematous.

\section{Histopathological Lesions:}

The lungs had focal purulent bronchopneumonia. The inter-aveolar septae were thickened by oedema fluid and purulent exudate. The aveolar walls were desquamated and the aveolar lumina were infiltrated by purulent exudate consisting of neutrophils, nectrotic debris, red blood cells and desquamated aveolar cells.

There were focal areas of haemorhage in the myocardial tmuscles of the right and left ventricles in ohe goat. The hepatic central veins were filled with blood. Lymphocyytes were sparsely distributed in the lymphoid nodules of the spleen of 3 goats.

The kidneys were congested and had tubular necrosis and desquamation of tubular epithelium. There were proteinaceous casts in the Bowman's capsule and the tubular lumina. There was minimal lyphocytic inflitration into the interstial tissues.

There was erosion of the epithelium of the urinary bladder. The cerebral blood vessels were congested. There was inflamation of the abomasum, small and large intestines characterized by congestion, epithelial necrosis and desquamation and neutrophilic infiltration of the submucosa.

\section{DISCUSSION}

Uraemia in farm animals is usually due to obstructive urolithiasis (Smith et al.,' 1972) and the ureteral ligation simulates such an obstruction. In this study, the survial time of the goats after ureteral ligation was $86-302$ hours. This time compares with $4-7$ days ( $96-188$ hours) reported by Vyas et al.(1978) in goats afte1 bilateral nephrectomy and $5-12$ days $(120-288$ hours)" reported by Jalaluddin et al. (1986) after ureteral ligation in calves.

Noticeable clinical effects of uraemia were observed 24 hours after surgery when anuria had set in. The clinical signs indicated disturbances in appetite, respiration and excitability which 


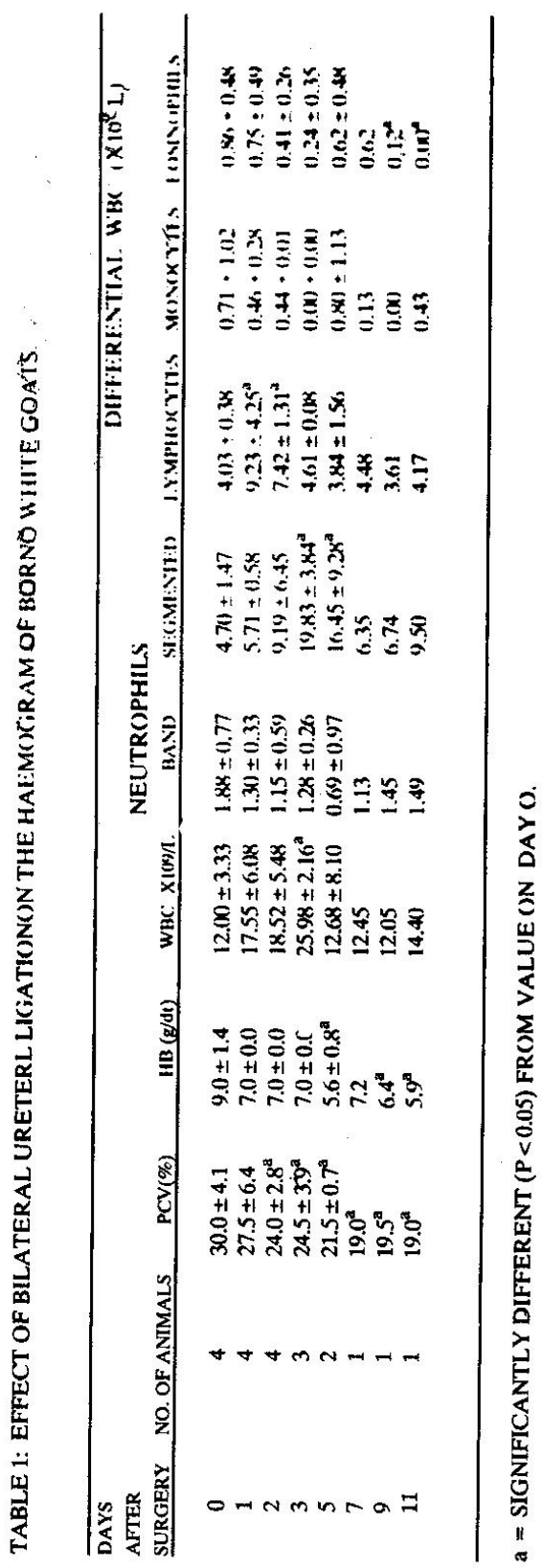


suggested the presence of organic lesions. The grinding of teeth may have been due to pain (Sharma et al., 1982).

The haematological changes after surgery were anaemia leucocytosis, lymphocyytosis, neutrophilia and eosinpenia. Prolonged uraemia has been reported to cause aneamia due to bone marrow depresion (Smith $e t$ al., 1972) The lymphocytosis, leucocytes changes may be associated with stress (Sharma et al.., 1982).

Ureteral ligation obstructs urine flow leading to anuria. The reflux of urine causes retention of toxic metabolites and may have applied pressure at the renal hilus creating a space between the capsule and the parenchyma for urine to accumulate in the subcapsular spaces as observed. Pressure and toxic'injury may have been responsible for the renal pathlogy observed which were similar to those described in calves by Jalaluddin et al.(1986) after bilateral ureteral ligation. The renal hypertension that was likely to have developed could have caused the hydrothorax and ascites observed. Because urine flow was stopped and the urinary bladder was not continuously flushed, the normal microbial flora in the bladder might have overgrrown to cause the pus observed in the bladder.

While Jalaluddin et al. (1986) reported congestion and focal naemorrhages in the lungs of calves after bilateral ureteral ligation, this study showed that the goats had focal purulent bronchopneumonia after similar surgical intervention. It appeared that the goats suffered more severe pulmonary injury than the calves. The respiratory lesions were therefore responsible for the coughing, inspiratory wheezing and laboured breathing shown by the goats.

The inflammatory reaction observed in the abomasum and intestine of the goats has been previously reported in uraemic dogs but buccal and pharyngeal ulcers reported in uraemic dogs were not observed (Smith et al., 1972). The gastronenteritis has been reported to be associated with the effect of toxic ammonia liberated from bacterial action on the urea in the gastrointestinal tract (Helmer and Batley, 1971). The nervous signs observed could be linked with the congestion and oedema of the brain which may have caused increased intracraninal pres- sure. Furthermore, it has been reported that convulsion in uraemic animals may be duto to lowering of blood calciuum (Smith et al., 1972). The disturbance in appetite was perhaps due to the central nervous system depression and the lessions in the gastrointentinal tract. The faeces of the goats were hard and scanty probably because of reduced feed and water intake (Simesen et at., 1979).

It is concluded that bilateral ureteral obstruction in Borno White goats would lead to severe lesions in the kidneys, lungs and gastrointestinal tract.

Clinical obstructions in the ureters or lower in the urinary tract therefore require early diognosis and surgical intervention to prevent the untoward effects which would lead to death within a few days. An expanded study on the pathological effects of urinary retention in the Borno White goats is going on and a more comprehensive picture will emerge in future.

\section{REFERENCES}

BLOOD, D.C., RADOSTITS, O.M. and HENDERSUN J.A. (1983) Veterinary Medicine. 6th ed. Bailliere Tindall, London. pp 348-352.

CHATFIELD, C. (1983) Statistics for technology. a course in applied statistics. 3rd ed, Chapman and Hall, New York. pp. 134-147.

DRUBY, R.A.B. and WALLINGTON, E.A. (1967) Carleton's Histoloogical Technique, 4th ed. Oxford University Press, London, pp114-137.

HELMER, L.G., and BARTLEY, E.E. (1971) Progress in the Utilizationn of urea as a proper replacer for ruminants: A rcvicw.J. Dairy Sci. 54, 25-32.

JALALUDDIN. A.M., SOBTI, V.K., PRASA, B., NAPPAL, S.K. and (iUPTAL, P.P. (1986) Histopathological changes following bilateral ureteral ligation and total nephrectomy in calves. Indion Vet. $J$ 63, 362-364. 
SCHALM, O.W., JAIN, N.C. and CARROLL, E.J. (1975) Veterinary Haematology. Lea \& Febiger, Philadelphia.

SHARMA, S.N., PRASAD, B., KOHLI., R.N. and SINGH, J. (1982) Pathophysiology of bovine uraemia, Indian J. Anim. Sci. 52, 643-649.

SIMESEN, M.G., AALUND, O. and HUSAGER, L. (1979) Biochemical changes following bilateral nephrectomy in the ovine. Acta Vet. Scandinavica 20, 595-597.

SMITH. H.A., JONES, T.C. and HUNT, R.D. (1972) Veterinary Pathology 4th ed. Lea and Febiger, Philadelphia. pp 1294-1295.
VYAS, U.K., ARYA, P.L. and SHARMA, S.N. (1978) Studies on exparimentally produced uraemia in sheep and goats. Indian J. Anim. Sci. $48,749-753$

WATTS, C. and CAMPBELL, J.R. (1970). Biochemical changes following bilateral nephrectomy in bovine. Res. Vet. Sci. 11, 508-514.

WATTS, C. and CAMPBELL, J.R. (1971). Fur ther studies on the effect of total nephrectomy in the bovine. Res. Vet. Sci. 12, 234 245. 